\title{
Epigenotoxicity of environmental pollutants evaluated by a combination of DNA methylation inhibition and capillary electrophoresis-laser-induced fluorescence immunoassay
}

\author{
Xiaoli Wang • Hailin Wang \\ Received: 7 November 2012 /Revised: 16 December 2012 / Accepted: 9 January 2013 / Published online: 2 February 2013 \\ (C) Springer-Verlag Berlin Heidelberg 2013
}

\begin{abstract}
A variety of environmental pollutants may cause abnormal DNA methylation, which further disturb gene expression. In this work, we developed a rapid and sensitive method for the characterization and identification of the epigenotoxicity of environmental pollutants in terms of DNA methylation. The method combines in vitro inhibition reactions of a model DNA methyltransferase (DNMT) with rapid and sensitive capillary electrophoresis-laser-induced fluorescence (CE-LIF) immunoassays. This method was first assessed using two known DNMT inhibitors, (-)-epigallocatechin-3-gallate and RG108, and then applied to epigenotoxic evaluation of four aldehydes and six benzo-1,4-quinones. It was found that all these electrophilic chemicals could inhibit DNMT activity, probably due to their interactions with the active sites of DNMT. Interestingly, benzo-1,4-quinones displayed more inhibitory effects on DNMT activity than aldehydes. Among the tested six benzo-1,4-quinones, halogenated benzo-1,4-quinone showed higher inhibitory activity than non-halogenated $p$-benzo-1,4-quinone. Owing to its speed and sensitivity, our method will be potentially applicable for fast epigenotoxic screening of environmental pollutants and mechanistic study of environmental epigenetics.
\end{abstract}

ABC Highlights: authored by Rising Stars and Top Experts.

X. Wang $\cdot H$. Wang $(\bowtie)$

State Key Laboratory of Environmental Chemistry

and Eco-toxicology, Research Center for Eco-Environmental

Sciences, Chinese Academy of Sciences,

Beijing, China 100085

e-mail: hlwang@rcees.ac.cn

X. Wang

Key Laboratory for Applied Technology of Sophisticated

Analytical Instruments of Shandong Province, Analysis

and Test Center, Shandong Academy of Sciences,

Jinan, China 250014
Keywords Environmental pollutants · Epigenotoxicity · DNA methylation · DNA methyltransferase · Capillary electrophoresis-laser-induced fluorescence immunoassay

\section{Introduction}

DNA methylation, catalyzed by DNA methyltransferases (DNMTs), is one of the best characterized epigenetic modifications, which can regulate gene expression without altering the primary structure of genomic DNA. It plays crucial roles in a variety of biological processes, such as genomic imprinting, $\mathrm{X}$-chromosome inactivation, regulation of chromatin organization, and cell differentiation [1-3]. Aberrant changes in DNA methylation, manifested as gene-specific hypermethylation and global hypomethylation, may disturb normal biological functions. Abnormal DNA methylation has been found in cancer as well as other human diseases [4-6], and the alteration of methylation status frequently occurs at an early stage of tumor malignant transformation [7, 8]. A number of environmental pollutants, including heavy metals and persistent organic pollutants, may directly or indirectly cause alterations of DNA methylation [9-11]. Surprisingly, the epigenetic changes induced by environmental chemicals could be heritable over several generations [12], providing a new perspective to the toxicological study of environmental pollutants [13, 14]. Identification and evaluation of the epigenetic effects and mechanisms of environmental contaminants is one of the major objectives of toxicological and biomedical research $[15,16]$. On the other hand, DNA methylation may be a useful biomarker for the toxicity evaluation of environmental chemicals and early diagnosis of pollutant-induced human disease [17].

Regarding the multitude of chemicals present in the environment, fast and high-throughput methods are highly desirable for screening and characterization of their epigenetic toxicity [18]. Nuclear extract containing DNA methyltranferase 
activity has been exploited to evaluate the metal epigenotoxicity [19]. Methylation levels from the reaction system were detected by high-performance liquid chromatography/mass spectrometry. However, the time-consuming process of DNA digestion used in that method limits its application for high-throughput screening [20-22]. We have developed a rapid and sensitive method for detection of genomic DNA methylation using capillary electrophoresis (CE) coupled with laser-induced fluorescence (LIF) immunoassay [23]. By taking advantage of the immunerecognition of 5-methylcytosine in genomic DNA, global DNA methylation of diverse genomic DNA samples could be assayed by highly sensitive CE-LIF immunoassay after direct incubation with specific anti-5-methylcytosine monoclonal antibody without the need of enzymatic digestion [23].

In this work, a model DNA methylation reaction is established using pure E. coli $\mathrm{CpG}$ methyltransferase M. Sss I, which recognizes the same sequence $\mathrm{CpG}$ as mammalian DNMTs and has relatively stronger catalytic activity [24]. Such pure enzyme-based methylation reaction can provide explicit inhibitory information. DNA methylation levels affected by environmental chemicals are detected by CE-LIF immunoassay. Therefore, a fast and sensitive epigenetic toxicity assessment of environmental pollutants could be performed successfully by the combination of in vitro DNMT model system and CE-LIF immunoassay (Scheme 1). Effects of aldehydes and quinones on DNA methylation status are then investigated. Both types of chemicals are electrophilic, and can react with protein and DNA to form adducts $[25,26]$. Howev$\mathrm{er}$, the study of their epigenotoxicology lacks. Identification of the epigenotoxicity will be helpful for in-depth study on their pathogenic mechanisms. Taking advantage of the high speed and sensitivity, our method will be applicable for epigenotoxic evaluation and pathogenetic mechanism study of the ubiquitous environmental pollutants in terms of DNA methylation.

\section{Materials and methods}

Chemicals and reagents

RG108, (-)-epigallocatechin-3-gallate (EGCG), formaldehyde, acetaldehyde, Tetrachloro-1,4-benzoquinone (TCBQ), 2,5-dichloro-1,4-benzoquinone (2,5-DCBQ), 2,6dichloro-1,4-benzoquinone (2,6-DCBQ), 2-chloro-1,4-benzoquinone (2-CBQ), 1,4-benzoquinone (p-BQ) and lambda DNA were all obtained from Sigma (St. Louis, MO, USA). 2,3-Dichloro-1,4-benzoquinone (2,3-DCBQ) was kindly provided by Dr. Benzhan Zhu (Research Center for Ecoenvironmental Sciences). Acrolein and crotonaldehyde were purchased from Aladdin Reagent Company (Shanghai, China). Mouse anti-methylcytosine monoclonal antibody (subclass: $\operatorname{IgG}_{1}$ ) was obtained from Calbiochem (La Jolla, CA, USA). Alexa Fluor 546 labeled goat anti-mouse $\operatorname{IgG}_{1}$ fragment Fab (secondary antibody) was supplied by Invitrogen (Carlsbad, CA, USA). E. coli CpG methyltransferase M. Sss I was purchased from New England BioLabs (Ipswich, MA, USA). Other chemicals in this experiment were supplied by Sigma (St. Louis, MO, USA) and Fisher Scientific (Pittsburgh, PA, USA).

Scheme 1 Sketch map of our project Environmental pollutants were added to the DNMTs-mediated methylation system. Its methylation level was precipitated and methylation level was detected by CE-LIF immunoassay. Environmental chemicals with epigenotoxicity may be identified according to their inhibitory effect on the in vitro methylation system

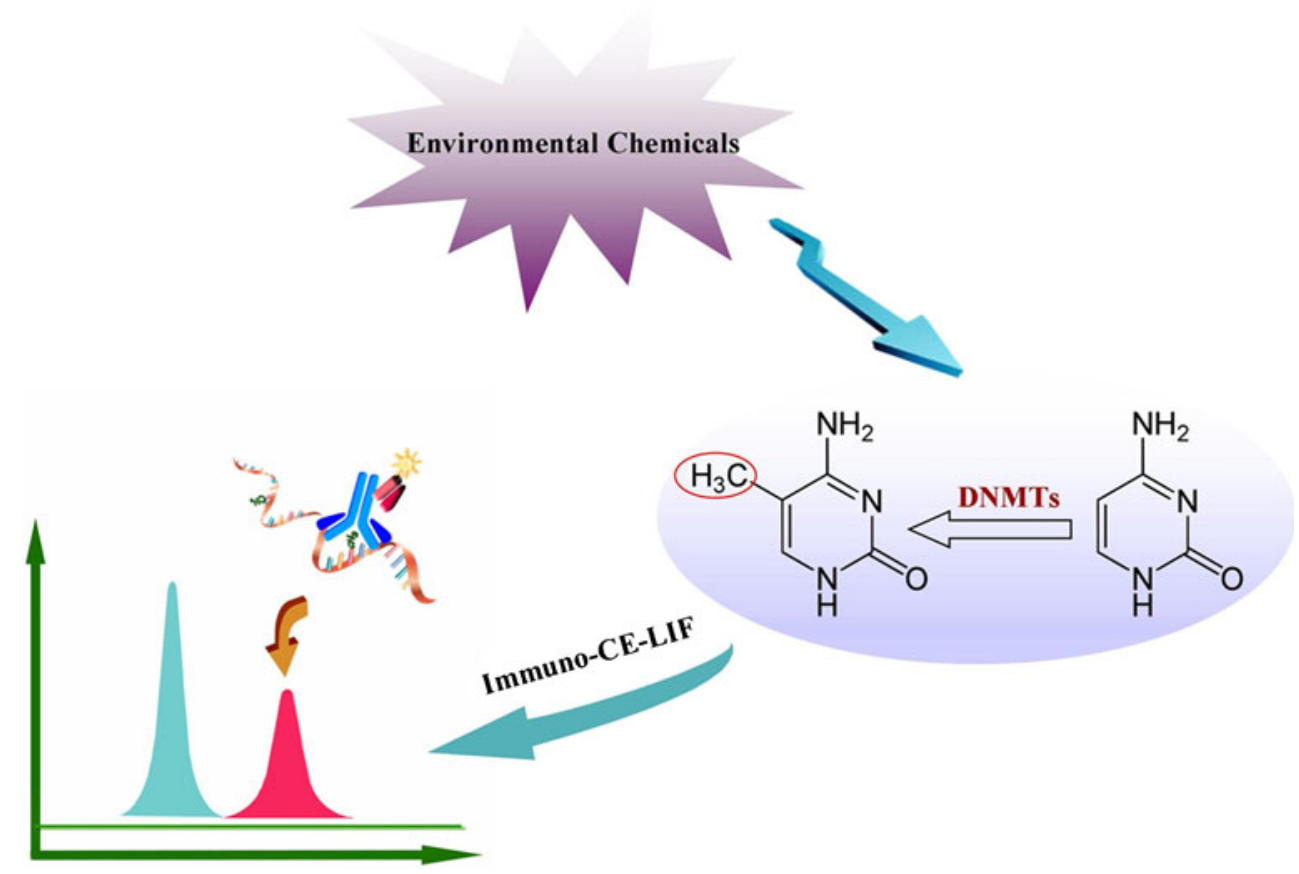




\section{CE-LIF Immunoassay for detection of DNA methylation}

CE-LIF immunoassay was performed on the laboratory-build CE-LIF system [27, 28]. A $543.5 \mathrm{~nm}$ helium-neon green laser ( $1 \mathrm{~mW}$, Melles Griot, Irvine, CA) was used for excitation and emitted fluorescence measured by photomultiplier tubes (PMT, Model R1477, Hamamatsu Photonics, Japan) at $575 \mathrm{~nm}$. Methylated lambda DNA was denatured by heating at $95{ }^{\circ} \mathrm{C}$ for $5 \mathrm{~min}$ and then chilled on ice to prevent from DNA re-annealing. The denatured DNA was mixed with $1 \mu \mathrm{g} / \mathrm{mL}$ primary antibody (mouse anti-methylcytosine monoclonal antibody), and $2 \mu \mathrm{g} / \mathrm{mL}$ secondary antibody (Alexa Fluor 546 labeled $\mathrm{F}_{\mathrm{ab}}$ fragment of goat anti-mouse $\left.\mathrm{IgG}_{1}\right)$ in sample buffer $(2 \times$ TGA, $14 \mathrm{mM}$ Tris, $108 \mathrm{mM}$ Glycine, HAc $10.5 \mathrm{mM}, \mathrm{pH} 7.5)$. Samples were vortexed gently and incubated at $4{ }^{\circ} \mathrm{C}$ before CE-LIF analysis. Uncoated fused-silica capillaries of $25 \mu \mathrm{m}$ i.d. $\times 365 \mu \mathrm{m}$ o.d. (Yongnian Optic Fiber Plant, Hebei, China) was $27 \mathrm{~cm}$ long with an effective length of $20 \mathrm{~cm}$. The samples were electrokinetically injected into capillary by applying a voltage of $15 \mathrm{kV}$ for $5 \mathrm{~s}$ and were separated by a voltage of $20 \mathrm{kV}$ at room temperature. The buffer of $1 \times$ TG $(30 \mathrm{mM}$ Tris and $160 \mathrm{mM}$ Glycine, pH8.5) was used as separation buffer. After each analysis, capillary was re-conditioned with $0.02 \mathrm{M} \mathrm{NaOH}$ for $5 \mathrm{~min}$ followed by water and running buffer for $5 \mathrm{~min}$.

\section{Method development using known DNMTs inhibitor}

CpG methyltransferase M. Sss I (0.2 U) and $100 \mu \mathrm{M}$ DNMTs inhibitor, EGCG or RG108, were mixed in the reaction buffer $(50 \mathrm{mM} \mathrm{NaCl}, 10 \mathrm{mM}$ Tris- $\mathrm{HCl}, 10 \mathrm{mM}$ EDTA, pH 7.9). Unmethylated lambda DNA (2 $\mu \mathrm{g})$ and $S$-adenosyl-L-methionine (SAM, $320 \mu \mathrm{M}$ ) were added subsequently in a final volume of $40 \mu \mathrm{L}$. The methylation reactions were done at $37{ }^{\circ} \mathrm{C}$ for $2 \mathrm{~h}$ and then inactivated at $65{ }^{\circ} \mathrm{C}$ for $15 \mathrm{~min}$. The methylated DNA was precipitated with isopropanol. The pellets was washed with $70 \%$ ethanol and re-suspended in sterilized $\mathrm{ddH}_{2} \mathrm{O}$. The concentration and quality of DNA were estimated by measuring the absorbance at 260 and $280 \mathrm{~nm}$. The methylation of DNA sample was evaluated by CE-LIF immunoassay. Effects of DNMTs inhibitors on DNA methylation reaction were evaluated by the methylation level of lambda DNA.

Effect of aldehydes and quinones on DNA methylation

Effects of formaldehyde, acetaldehyde, acrolein, and crotonaldehyde $(1,000 \mu \mathrm{M})$ on DNA methylation were evaluated in the reaction system as described above. Inhibitory effect of different concentrations of acrolein (0, 1, 10, 100, $1,000 \mu \mathrm{M})$ on DNMTs activity was also assayed.
To evaluated the effect of potential DNA damage induced by aldehydes on methylation reactions, lambda DNA $(2 \mu \mathrm{g})$ and $100 \mu \mathrm{M}$ acrolein were mixed and incubated at $37^{\circ} \mathrm{C}$ for 2 h. Lambda DNA was then precipitated with isopropanol and washed by $70 \%$ methanol. Purified lambda DNA was re-suspended in sterilized $\mathrm{ddH}_{2} \mathrm{O}$. During this process, hydrophobic acrolein could be removed. Lambda DNA reacted with and without acrolein were catalyzed by $\mathrm{M}$.
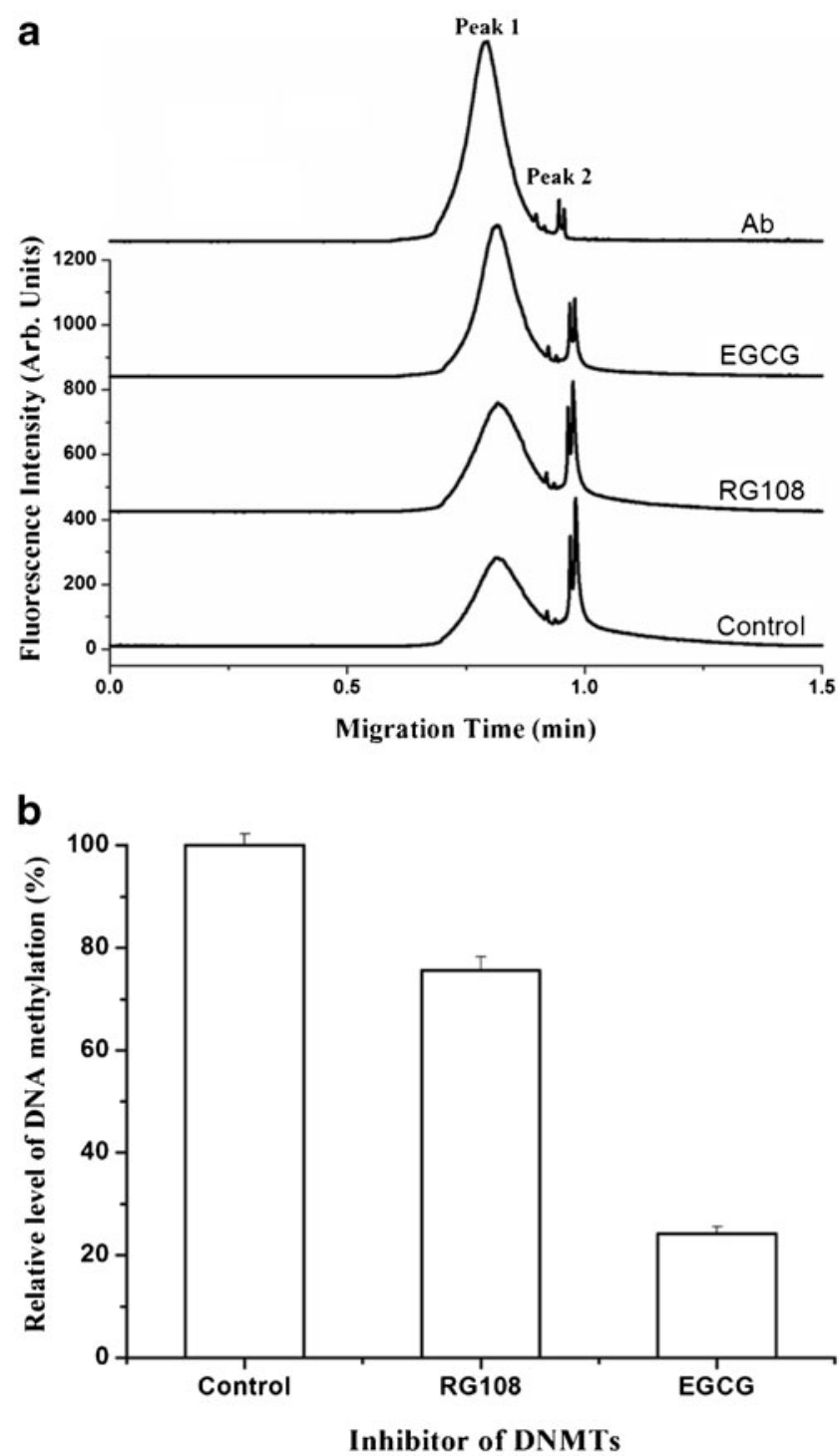

Fig. 1 CE-LIF immunoassay for the inhibitory effect of DNMTs inhibitors EGCG and RG108 on methylation reaction. a Trace "Ab" was obtained from CE-LIF analysis of the mixture of primary and secondary antibody. Traces "EGCG", "RG108", and "positive control" were correspondingly obtained from CE-LIF analysis of methylated lambda DNA obtained from reaction system disturbed by EGCG, RG108 and the control group (without any inhibitor). Peak 1 complex of primary antibody and secondary antibody; peak 2 the immunocomplex of methylated DNA (primary antibody-secondary antibodymethylated lambda DNA). b Statistical result of the CE-LIF immunoassay. The detail conditions for CE-LIF immunoassays see "Materials and methods" section 
Sss $\mathrm{I}$ at $37^{\circ} \mathrm{C}$ for $2 \mathrm{~h}$, and DNA methylation levels were evaluated by CE-LIF immunoassay.

Inhibitory effects of quinones on DNA methylation system were also detected using CE-LIF immunoassay. TCBQ, 2,3-DCBQ, 2,5-DCBQ，2,6-DCBQ，2-CBQ, and $\mathrm{p}-\mathrm{BQ}$ were dissolved in acetonitrile $(\mathrm{ACN})$, and added to the reaction system with the concentration of $30 \mu \mathrm{M}$. Reaction system only with same volume of ACN was used as positive control. Different concentrations of 2,3-DCBQ and p-BQ $(0,0.1,1,10$, and $100 \mu \mathrm{M})$ were selected for the dose-effect relationship detection.

All the experiments were performed three times and the average was displayed in the histograms with error bars representing the standard deviation.

\section{Results and discussion}

Rapid assessment of DNA methylation inhibitory activity

To test the feasibility of our method, two known DNMT inhibitors (EGCG and RG108) were used. The interactions of the two inhibitors with E. coli $\mathrm{CpG}$ methyltransferase M. Sss I might inhibit the catalytic activity and reduce the degree of the methylation of DNA. EGCG, the major polyphenol component extracted from green tea, was reported to inhibit DNMT1 activity by tethering within binding site through hydrogen bonds involving $\mathrm{Ser}^{1229}$, $\mathrm{Glu}^{1265}$, $\mathrm{Pro}^{1223}$, and $\mathrm{Cys}^{1225}$ [29] and RG108, N-phthalyl-L-tryptophan selected through computer simulation, was identified as a human DNMT1 inhibitor [30]. To perform the DNA methylation a

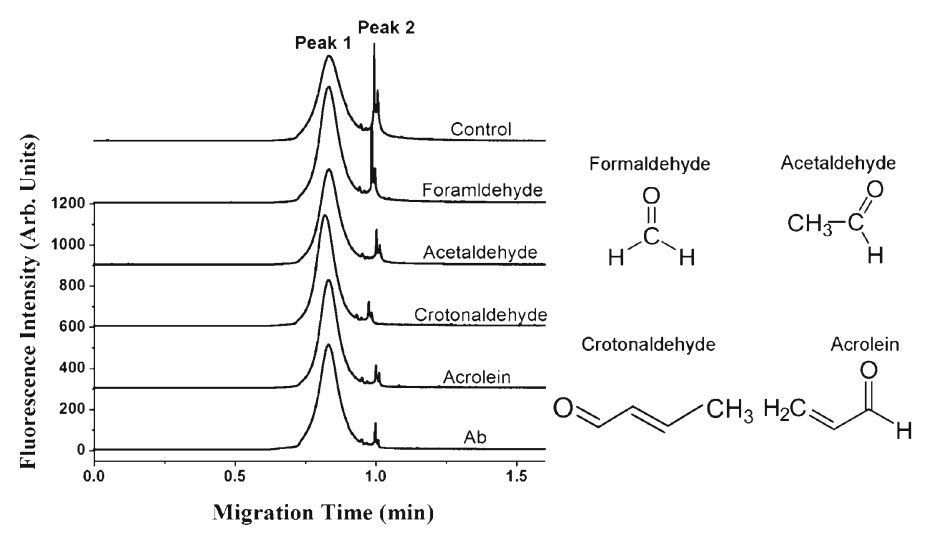

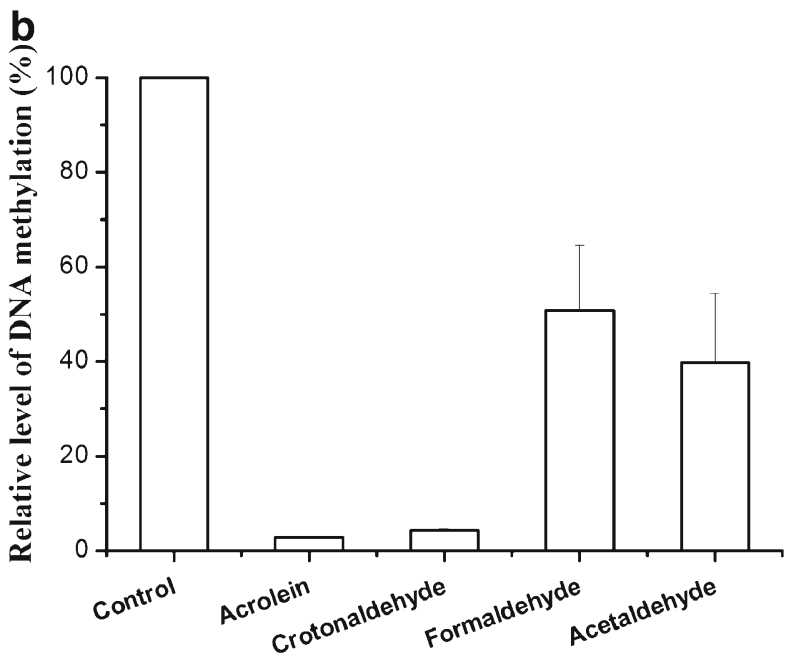

d

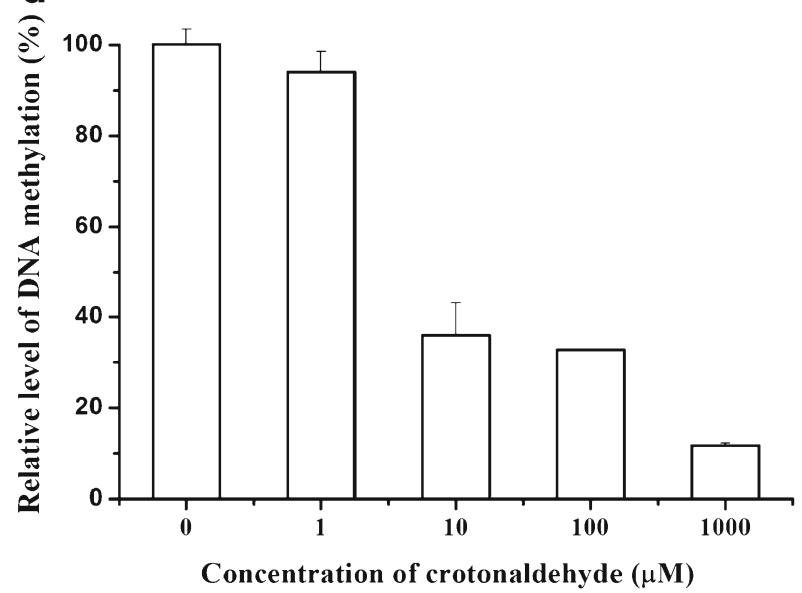

from reaction system disturbed by formaldehyde, acetaldehyde, acrolein and crotonaldehyde. Peak 1 complex of primary antibody and secondary antibody; peak 2 the immunocomplex of methylated DNA. b Statistical result of Fig. 2a. c Inhibitory effects of a series of acrolein with different concentrations $(0,1,10,100,1,000 \mu \mathrm{M})$ on methylation reaction. d Inhibitory effects of different concentrations of crotonaldehyde $(0,1,10,100,1,000 \mu \mathrm{M})$ on methylation reaction 
inhibition test, DNMT inhibitor (EGCG or RG108) was added to methylation reaction system and methylation levels were assayed immediately by CE-LIF immunoanalysis.

Lambda DNA from the reaction system was incubated with primary and second antibody, and the immunocomplex of methylated DNA were detected by CE-LIF. Interestingly, only one antibody peak was observed (Fig. 1a). This is consistent with our previous work [23], which showed that the secondary antibody cannot be separated from its complex with primary antibody by free zone CE and overlapped as one peak (peak 1, Fig. 1a). Moreover, since the primary antibody has two binding sites, it is reasonable to believe that two immunocomplexes of antibody-methylated DNA can be observed. Indeed, we observed that there are two complexes of two antibodies and methylated DNA as showed by split peak 2 (Fig 1a). The peak area ratio of peak 2 to peak 1 could be used for the accurate quantification of DNA methylation level. To display clearly the changes of DNA methylation levels, we assembled the chromatograms in one figure with the same axis, and the chromatograms were staggered in the $y$-axis to avoid overlap.

In contrast to the positive control (without methylation inhibitor), the intensity of the immune complex of methylated DNA in the EGCG-treated M. Sss I reaction decreased significantly, while that in the RG108-treated M. Sss I reaction also decreased but with relatively low inhibitory degree. These results suggest that the methylation of DNA is obviously inhibited by both EGCG and RG108 (Fig. 1b). The inhibitory percentages of EGCG and RG108 are about 71 and $24 \%$, respectively. The result confirmed that our method could be applied for in vitro epigenotoxic screening of environmental chemicals with its high sensitivity and speed.

\section{Epigenotoxic evaluation of four aldehydes}

Early studies indicated that aldehyde compounds may induce genotoxicity through the formation of DNA adducts, DNA strand breaks, DNA-DNA, and DNA-protein crosslink [26]. Formaldehyde, one of the typical aldehyde compounds, is a common indoor air pollutant, which can cause serious damage to human respiratory system and has been classified as group 1A (human carcinogen) by International Agency for Research on Cancer [31]. Toxicity of $\alpha, \beta$-unsaturated aldehydes, such as acrolein and crotonaldehyde, are partly attributable to its high reactivity toward DNA and proteins through Michael addition reaction $[32,33]$. Recent study suggested that acrolein not only induced DNA damage, but also inhibited excision repair and mismatch repair that might cause mutagenesis and initiate carcinogenesis [34]. However, it is not clear whether the reactive and electrophilic aldehydes can inhibit DNA methylation and cause epigenetoxicity.
All DNA methyltransferases have a conservative proline-cysteine dipeptide, which is known to be the most important part of the catalytic domain, and cysteine thiolate provided by the conservative dipeptide has been proved to be essential for the initiation of methyl group transfer reaction [35]. So, we hypothesized that DNA methylation level might be affected by aldehydes which could react with the proline-cysteine dipeptide at active sites of DNMTs through Michael addition reaction.

For in vitro epigenotoxicity evaluation of aldehydes, $1 \mathrm{mM}$ of formaldehyde, acetaldehyde, acrolein, and crotonaldehyde were added to the methylation reaction system, respectively. The inhibition of DNMTs activity could be observed in all aldehyde-containing reactions (Fig. 2a). Compared with the positive control group, the reduction of DNA methylation level induced by acrolein and crotonaldehyde is above $90 \%$ (Fig. 2b). Clearly, inhibition is dose dependent (Fig. 2c and d). Significant inhibition of DNMTs activity could be observed for acrolein or crotonaldehyde at a dosage of above $10 \mu \mathrm{M}$ (Fig. 2c and d).

It is not known whether the observed inhibition is due to the interactions of aldehydes with M. Sss I or due to aldehyde-caused DNA damage. To investigate the latter possibility, the effect of aldehyde-induced DNA damage on methylation reaction system is further evaluated. In such a case, lambda DNA is first treated with acrolein $(100 \mu \mathrm{M})$, and then the un-reacted acrolein is removed during the process of DNA purification. In such a treatment, it is supposed that the DNA damage in the treated lambda

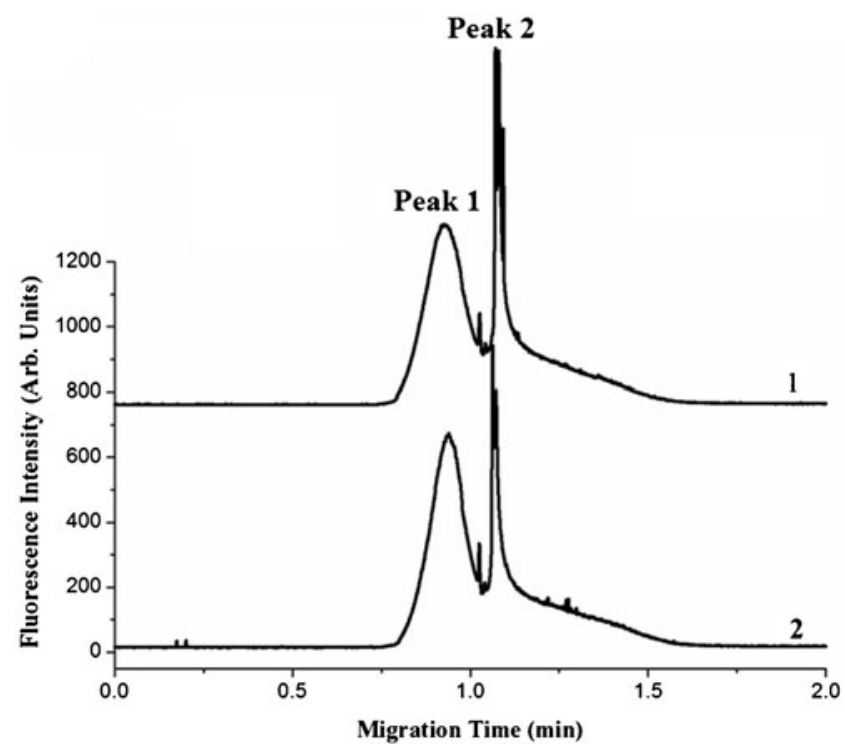

Fig. 3 Effect of acrolein-induced DNA damage on methylation reaction system was evaluated for the methylation inhibition mechanism investigation. Trace 1 was obtained from immuno-CE-LIF analysis of methylated lambda DNA. Trace 2 was obtained from CE-LIF immunoassay of methylated lambda DNA which was reacted with acrolein before catalyzed by M. Sss I. Peak 1 complex of primary antibody and secondary antibody; peak 2 the immunocomplex of methylated DNA 
DNA can be induced by acrolein. The readily damaged lambda DNA is further methylated by M. Sss I. Interestingly, no inhibition on DNA methylation is observed. Compared with lambda DNA that is not reacted with acrolein (assumed as $100 \%$ ), no significant difference is detected in methylation level of the lambda DNA pretreated with acrolein (about $99 \%$ ) (Fig. 3). Our results indicate that the potential DNA damage caused by acrolein and other aldehydes cannot affect the methylation reaction obviously. Therefore, the observed inhibitory effect of acrolein on enzyme-catalyzed DNA methylation may mostly attribute to the reaction between aldehydes and the active sites of DNMTs.

\section{Epigenotoxic evaluation of quinones}

We further tested the inhibitory effect of quinones on DNA methylation as the second example. Quinones were found to cause multiple hazardous effects, e.g., immunotoxicity, cytotoxicity and carcinogenesis [25, 36]. 2,6-dichloro-1,4- benzoquinone (DCBQ), 2,6-dichloro-3-methyl-1,4-benzoquinone, and 2,6-dibromo-1,4-benzoquinone have been detected as new disinfection by-products in drinking water recently $[37,38]$. Quinones were reported to be able to react with thiol functional groups via Michael-type addition, so we hypothesized that the free cysteine residues of DNMTs located in their catalytic center may be modified by these compounds, leading to inhibition of their activities. Indeed, all the tested quinones, TCBQ, 2,3-DCBQ, 2,5-DCBQ, 2,6-DCBQ, 2-CB, and p-BQ, showed the significant inhibition on DNA methylation reaction when $30 \mu \mathrm{M}$ quinones were added in the reaction system (Fig. 4a). The observed inhibitory potency of the tested quinones is higher than the tested aldehyde compounds (Fig. 4a vs Fig. 2a). Although quinones may cause damage to DNA, the formation of the oxidation DNA damage is very low $(<0.1 \%)$. The observed inhibition is reasonable to be attributed to the interaction of quinones with the DNMT.

DNA methylation reaction can be disturbed by different concentrations of 2,3-DCBQ $(0,0.1,1,10$, and $100 \mu \mathrm{M})$ as

a
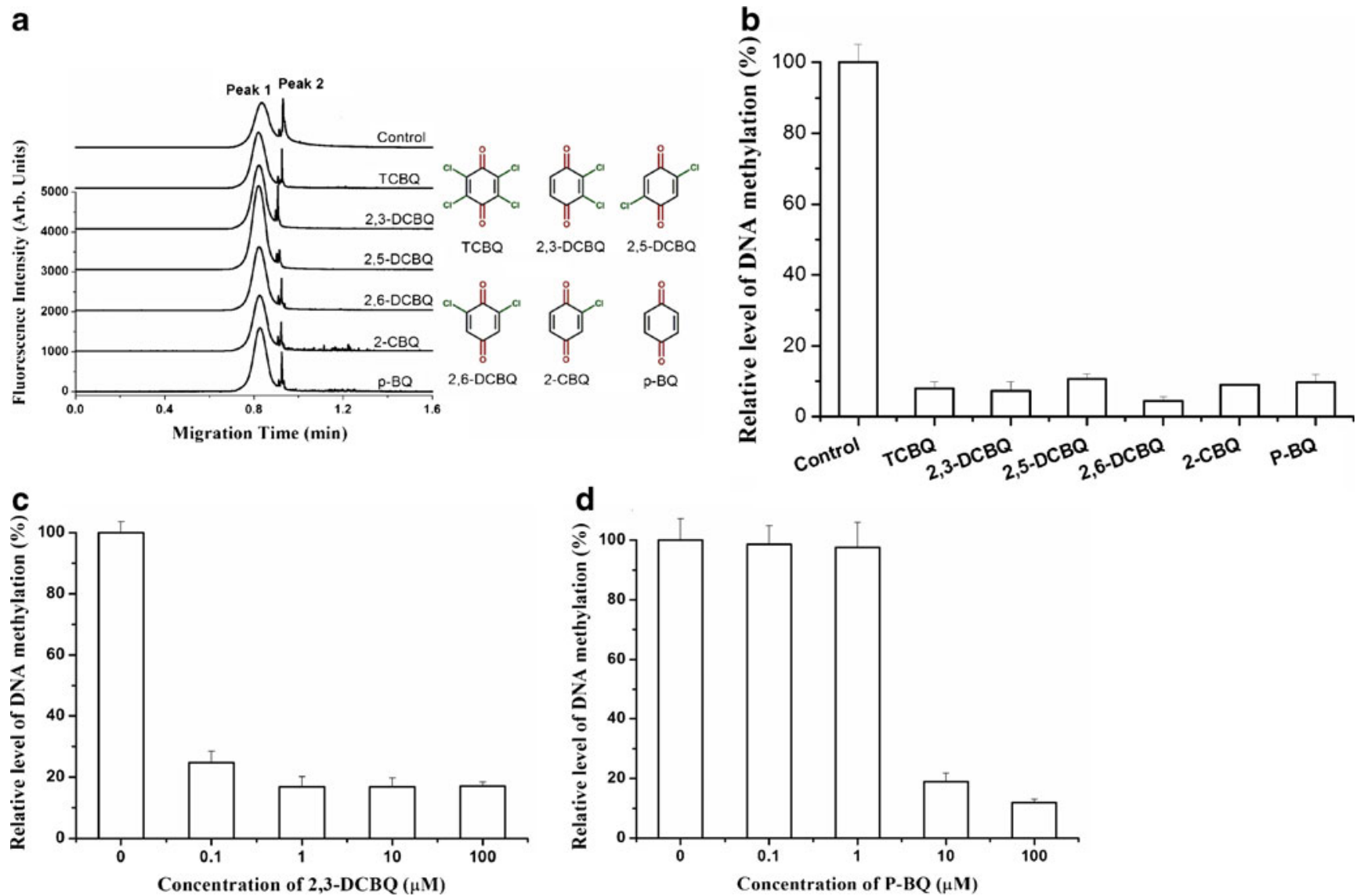

Fig. 4 Effect of quinones on methylation reaction detected by immuno-CE-LIF. a Methylated lambda DNA precipitated from reaction system which contained $30 \mu \mathrm{M}$ quinines was assayed by immunoCE-LIF. The detail conditions for CE-LIF immunoassays see experimental section. Traces "TCBQ", "2,3-DCBQ", "2,5-DCBQ", "2,6DCBQ", "2-CBQ" and " $p-B Q$ " were correspondingly obtained from CE-LIF analysis of methylated lambda DNA obtained from reaction

system disturbed by TCBQ, 2,3-DCBQ, 2,5-DCBQ, 2,6-DCBQ, 2CBQ and p-BQ. Peak 1 complex of primary antibody and secondary antibody; peak 2 the immunocomplex of methylated DNA. b Statistical result of Fig. 4a. c Inhibitory effects of different concentrations of 2,3DCBQ $(0,0.1,1,10,100 \mu \mathrm{M})$ on methylation reaction. $\mathbf{d}$ Inhibitory effects of a series of $\mathrm{p}-\mathrm{BQ}$ with different concentrations $(0,0.1,1,10$, $100 \mu \mathrm{M}$ ) on methylation reaction 
detected by CE-LIF immunoassay. Significant decrease of methylation level (about $75 \%$ ) is detected even treated with 2,3-DCBQ as low as $0.1 \mu \mathrm{M}$, while decrease is not significant when treated by 2,3-DCBQ at lower concentration and the reason is not clear (Fig. 4c). Inhibitory effect of p-BQ $(0$, $0.1,1,10$, and $100 \mu \mathrm{M}$ ) on DNMTs activity is also observed and the reaction system is disturbed obviously when $10 \mu \mathrm{M}$ of p-BQ was added (Fig. 4d). Compared with un-substituted $\mathrm{p}-\mathrm{BQ}$, halogenated quinones exhibited higher inhibitory effects (Fig. $4 \mathrm{c}$ and d), indicating the halogenation of quinones can enhance the inhibitory effects of quinones on DNA methylation reactions.

Based on our data, we may speculate that quinones may induce aberrant DNA methylation in vitro as well as in vivo through the inhibition of DNMTs activity in catalyzing cytosine methylation. By combining the in vitro methylation reaction and CE-LIF immunoassay, inhibitory effect of various quinones on DNMTs activity could be evaluated sensitively.

Epigenotoxic evaluation of electrophilic compounds (as demonstrated by aldehydes and quinones) may provide a new approach for elucidation of the toxic mechanism and will be helpful for the control and early diagnosis of electrophilic compounds-induced human disease. In addition, by combining with 96 array capillary electrophoresis, our method may provide the high-throughput analysis, and it will be useful for large-scale screening and in-depth studies of epigenotoxic effects of the ubiquitous environmental pollutants.

In summary, highly sensitive CE-LIF immunoassay is developed for the epigenotoxicity evaluation of environmental chemicals in combination with M. Sss I-mediated DNA methylation reaction as a model system. With the high speed, sensitivity and specificity of CE-LIF immunoassay, our method will be helpful for detection of aberrant DNA methylation induced by environmental pollutants. Our study may suggest the inhibitory effects of quinones and aldehydes on DNMTs activity. Our method will be useful for the epigenotoxic evaluation of environmental pollutants and the epigenetic mechanism study of environmental-related human diseases.

Acknowledgments The work was supported by the Grants from the National Basic Research Program of China (2009CB421605 and 2010CB933502) and the National Natural Science Foundation of China $(21077129,20877091,20890112,21125523$, and 20921063) to Dr. H. Wang.

\section{References}

1. Jones PA, Takai D (2001) The role of DNA methylation in mammalian epigenetics. Science 293(5532):1068-1070

2. Singal R, Ginder GD (1999) DNA methylation. Blood 93(12):40594070
3. Kumar S, Cheng X, Klimasauskas S, Mi S, Posfai J, Roberts RJ, Wilson GG (1994) The DNA (cytosine-5) methyltransferases. Nucleic Acids Res 22(1):1-10

4. Ehrlich M (2002) DNA methylation in cancer: too much, but also too little. Oncogene 21(35):5400-5413

5. Kim YI, Giuliano A, Hatch KD, Schneider A, Nour MA, Dallal GE, Selhub J, Mason JB (1994) Global DNA hypomethylation increases progressively in cervical dysplasia and carcinoma. Cancer 74 (3):893-899

6. Esteller M, Corn PG, Baylin SB, Herman JG (2001) A gene hypermethylation profile of human cancer. Cancer Res 61(8):3225-3229

7. Robertson KD (2005) DNA methylation and human disease. Nat Rev Genet 6(8):597-610

8. Momparler RL (2003) Cancer epigenetics. Oncogene 22(42):64796483

9. Anway MD, Cupp AS, Uzumcu M, Skinner MK (2005) Epigenetic transgenerational actions of endocrine disruptors and male fertility. Science 308(5727): 1466-1469

10. Salnikow K, Zhitkovich A (2008) Genetic and epigenetic mechanisms in metal carcinogenesis and cocarcinogenesis: nickel, arsenic, and chromium. Chem Res Toxicol 21(1):28-44

11. Rusiecki JA, Baccarelli A, Bollati V, Tarantini L, Moore LE, Bonefeld-Jorgensen EC (2008) Global DNA hypomethylation is associated with high serum-persistent organic pollutants in Greenlandic Inuit. Environ Health Perspect 116(11):1547-1552

12. Jirtle RL, Skinner MK (2007) Environmental epigenomics and disease susceptibility. Nat Rev Genet 8(4):253-262

13. Bollati V, Baccarelli A (2010) Environmental epigenetics. Heredity (Edinb) 105(1):105-112

14. Weinhold B (2006) Epigenetics: the science of change. Environ Health Perspect 114(3):A160-167

15. De Rosa CT (2003) Restoring the foundation: tracking chemical exposures and human health. Environ Health Perspect 111(7): A374-375

16. McGeehin MA, Qualters JR, Niskar AS (2004) National environmental public health tracking program: bridging the information gap. Environ Health Perspect 112(14):1409-1413

17. Szyf M (2011) The implications of DNA methylation for toxicology: toward toxicomethylomics, the toxicology of DNA methylation. Toxicol Sci 120(2):235-255

18. Edwards TM, Myers JP (2007) Environmental exposures and gene regulation in disease etiology. Environ Health Perspect 115 (9):1264-1270

19. Poirier LA, Vlasova TI (2002) The prospective role of abnormal methyl metabolism in cadmium toxicity. Environ Health Perspect 110(5):793-795

20. Friso S, Choi SW, Dolnikowski GG, Selhub J (2002) A method to assess genomic DNA methylation using high-performance liquid chromatography/electrospray ionization mass spectrometry. Anal Chem 74(17):4526-4531

21. Song L, James SR, Kazim L, Karpf AR (2005) Specific method for the determination of genomic DNA methylation by liquid chromatography-electrospray ionization tandem mass spectrometry. Anal Chem 77(2):504-510

22. Liu Z, Liu S, Xie Z, Blum W, Perrotti D, Paschka P, Klisovic R, Byrd J, Chan KK, Marcucci G (2007) Characterization of in vitro and in vivo hypomethylating effects of decitabine in acute myeloid leukemia by a rapid, specific and sensitive LC-MS/MS method. Nucleic Acids Res 35(5):e31

23. Wang XL, Song YL, Song MY, Wang ZX, Li T, Wang HL (2009) Fluorescence polarization combined capillary electrophoresis immunoassay for the sensitive detection of genomic DNA methylation. Anal Chem 81(19):7885-7891

24. Darii MV, Cherepanova NA, Subach OM, Kirsanova OV, Raskó T, Slaska-Kiss K, Kiss A, Deville-Bonne D, Reboud-Ravaux M, Gromova ES (2009) Mutational analysis of the CG recognizing 
DNA methyltransferase SssI: insight into enzyme-DNA interactions. Biochim Biophys Acta 1794(11):1654-1662

25. Bolton JL, Trush MA, Penning TM, Dryhurst G, Monks TJ (2000) Role of quinones in toxicology. Chem Res Toxicol 13(3):135-160

26. O'Brien PJ, Siraki AG, Shangari N (2005) Aldehyde sources, metabolism, molecular toxicity mechanisms, and possible effects on human health. Crit Rev Toxicol 35(7):609-662

27. Wang HL, Lu M, Tang MS, Van Houten B, Ross JB, Weinfeld M, Le XC (2009) DNA wrapping is required for DNA damage recognition in the Escherichia coli DNA nucleotide excision repair pathway. Proc Natl Acad Sci USA 106(31):12849-12854

28. Zhang DP, Lu ML, Wang HL (2011) Fluorescence anisotropy analysis for mapping aptamer-protein interaction at the single nucleotide level. J Am Chem Soc 133(24):9188-9191

29. Fang MZ, Wang Y, Ai N, Hou Z, Sun Y, Lu H, Welsh W, Yang CS (2003) Tea polyphenol (-)-epigallocatechin-3-gallate inhibits DNA methyltransferase and reactivates methylation-silenced genes in cancer cell lines. Cancer Res 63(22):7563-7570

30. Brueckner B, Garcia Boy R, Siedlecki P, Musch T, Kliem HC, Zielenkiewicz P, Suhai S, Wiessler M, Lyko F (2005) Epigenetic reactivation of tumor suppressor genes by a novel small-molecule inhibitor of human DNA methyltransferases. Cancer Res 65 (14):6305-6311

31. Cogliano VJ, Grosse Y, Baan RA, Straif K, Secretan MB, El Ghissassi F, Working Group for Volume 88 (2005) Meeting report: summary of IARC monographs on formaldehyde, 2-butoxyethanol, and 1-tert-butoxy-2-propanol. Environ Health Perspect 113(9):12051208

32. Voulgaridou GP, Anestopoulos I, Franco R, Panayiotidis MI, Pappa A (2011) DNA damage induced by endogenous aldehydes: current state of knowledge. Mutat Res 711(1-2):13-27

33. Cai J, Bhatnagar A, Pierce WM Jr (2009) Protein modification by acrolein: formation and stability of cysteine adducts. Chem Res Toxicol 22(4):708-716

34. Wang HT, Hu Y, Tong D, Huang J, Gu L, Wu XR, Chung FL, Li GM, Tang MS (2012) Effect of carcinogenic acrolein on DNA repair and mutagenic susceptibility. J Biol Chem 287(15):12379-12386

35. Bestor TH (2000) The DNA methyltransferases of mammals. Hum Mol Genet 9(16):2395-2402

36. Tsai CH, Lin PH, Waidyanatha S, Rappaport SM (2001) Characterization of metabolic activation of pentachlorophenol to quinones and semiquinone in rodent liver. Chem Biol Interact 134 (1):55-71

37. Qin F, Zhao YY, Zhao Y, Boyd JM, Zhou W, Li XF (2010) A toxic disinfection by-product, 2,6-dichloro-1,4-benzoquinone, identified in drinking water. Angew Chem Int Ed Engl 49(4):790-792

38. Zhao Y, Qin F, Boyd JM, Anichina J, Li XF (2010) Characterization and determination of chloro- and bromo-benzoquinones as new chlorination disinfection byproducts in drinking water. Anal Chem 82(11):4599-4605 